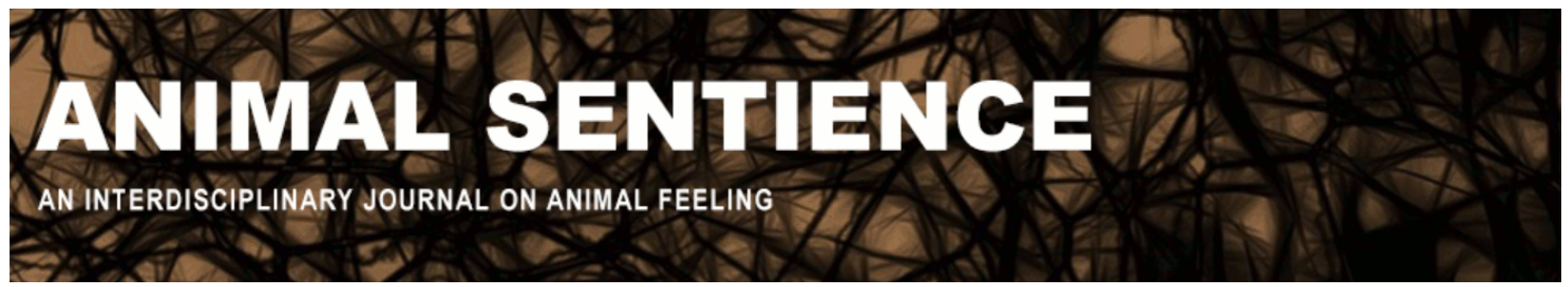

Rollin, Bernard (2019) Far more to sheep than meets the casual eye. Animal Sentience 25(7)

DOI: $10.51291 / 2377-7478.1440$

Date of submission: 2019-05-12

Date of acceptance: 2019-05-18 (c) 


\title{
Far more to sheep than meets the casual eye
}

Commentary on Marino \& Merskin on Sheep Intelligence

\author{
Bernard Rollin \\ Department of Philosophy \\ Colorado State University
}

\begin{abstract}
Marino \& Merskin's survey of the cognitive and social capacities of sheep is an eyeopener about the individuality and emotionality of this most maligned of all farm animals. My own eyes had already been opened by an adopted orphaned lamb, so much more like a dog as a companion animal than the mindless robot I had been conditioned to expect. I am morally certain that Marino \& Merskin's survey will have a similar effect on readers open to changing their minds.
\end{abstract}

Bernard Rollin is Distinguished
Professor of Philosophy, Animal
Sciences and Biomedical Sciences, at
Colorado State University. One of the
leading scholars in animal rights and
animal consciousness, he has lectured
worldwide. Website

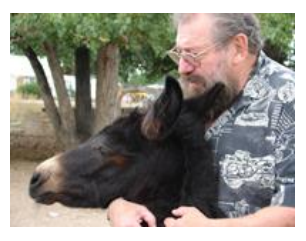

Marino \& Merskin's (2019) (M\&M) well-researched and well-reasoned essay continues to explode stereotypes pertaining to the intellectual and emotional content of the farm animal experience. Following her excellent papers on the same topic dealing with cattle and chickens, Marino turns to sheep, probably the most maligned of all farm animals.

While one might expect ordinary people to hold the view that there are minimal individual differences among sheep and that their mental lives are limited, I've been surprised to find the same view entertained far too often by people in the sheep business. There are a number of possible explanations for this. One is that people raising large groups of sheep tend to see them as flocks, not as individuals. In addition, not recognizing their psychological subtleties and individual differences may well serve as a protective psychological mechanism (Bastian et al. 2012; Harmon-Jones et al. 2017) for farmers who know that many of these animals are destined to die (between 2 and 2.5 million are slaughtered annually in the U.S.), and therefore try to distance themselves from empathetic relationships with the animals in their charge.

A similar pattern occurs in the case of young agricultural people involved in livestock showing. These youths spend hours grooming, handling, training, and bonding with the animals they show. When the show is over, they are often forced to load the animals into trucks taking them to slaughter. One of my friends, a major figure In the National Western Livestock Show in Denver, has regularly opined that this practice is insensitive to the young people who have put countless hours into bonding with the animals. Compelling these youngsters to directly involve themselves in trucking the animals to certain death borders on cruelty. I have discussed this with animal science students in my University, and the very conversation often leads them to tears. No 
wonder, then, that they emotionally distance themselves from the personhood that M\&M identify.

I am embarrassed to admit that I entertained an extremely narrow view of sheep emotion and intellect until one of my close friends adopted an orphaned lamb. The lamb followed her everywhere and interacted with her other animals - dogs, cats, horses and mules. He also evidenced significant intellectual and emotional variations in behavior. In fact, it was only through the good offices of my wife that I began to see the sheep for what he really was. In no uncertain terms, she communicated to me in a talk replete with examples, that the sheep was more like a dog as a companion animal than the mindless robot I was conditioned to expect.

In discussing this experience with some of my brighter agriculture students, they let me know in no uncertain terms that whenever one interacts with large groups of animals - be it sheep, cows, dogs or birds - the individuality of these animals is eclipsed, and what is attended to are repeatable and predictable traits (see Peña-Guzmán 2019).

M\&M's target article excels at finding generally unknown and publicly unrecognized emotional and intellectual traits of sheep in the literature. These findings are summarized in four categories: learning and cognition, emotions, personality, and social complexity. The traits M\&M describe are perfect for awakening surprise and indeed astonishment in ordinary people who think of sheep only in terms of stereotypes. Much to my surprise, attentional set-shifting is performed by sheep at a level on a par with humans and primates! Sheep are also capable of learning and remembering complex mazes for at least 22 weeks based on very few trials. They also excel at facial recognition. Sheep facial recognition capacity is on a par with humans.

Sheep do well in recognizing themselves in mirrors, a much touted (but in my view overrated) criterion for self-consciousness. Regarding emotion, M\&M cite evidence for a wide range of emotional states in sheep, overlapping with humans. For example, sheep display, based on their experience, what would be called in humans "optimism" and "pessimism." There is evidence that sheep are aware of being in control of a situation, and that this creates positive excitement in their minds. Sheep also exhibit "emotional contagion," believed by many scholars to be a foundation for empathy. Baby lambs recognize and bond with their mothers in as few as 12 hours after birth.

M\&M review a good deal of evidence of "social buffering" wherein individual animals react less intensely to stressful or fear-inducing situations when they are in the presence of conspecifics. Lambs will engage in play behavior and form playgroups within a week of birth. There is also extensive evidence of personality differences in sheep, including in shyness, boldness and gregariousness.

All of these data show clearly that sheep are far more complex intellectually and emotionally than they have been credited with even by people who raise them. For myself, I will never look at sheep in the same simplistic way that I did to reading this paper. I am morally certain that M\&M's survey will have a similar effect on readers open to changing their minds. 


\section{References}

Bastian, B., Loughnan, S., Haslam, N., \& Radke, H. R. (2012) Don't mind meat? The denial of mind to animals used for human consumption. Personality and Social Psychology Bulletin 38(2), 247-256.

Harmon-Jones, C., Haslam, N., \& Bastian, B. (2017) Dissonance reduction in nonhuman animals: Implications for cognitive dissonance theory. Animal Sentience 12(4)

Marino, L., \& Merskin, D. (2019) Intelligence, complexity, and individuality in sheep. Animal Sentience 25(1)

Peña-Guzmán, D. (2019) Casting a sheep's eye on science. Animal Sentience 25(6) 